\title{
On-line Estimation of Workpiece Height by Using Neural Networks and Hierarchical Adaptive Control of WEDM
}

\author{
M. T. Yan ${ }^{1}$, Y. S. Liao², C. C. Chang ${ }^{2}$ \\ ${ }^{1}$ Department of Mechanical Engineering, Huafan University, Taipei Hsien, Taiwan; and ${ }^{2}$ Department of Mechanical Engineering, \\ National Taiwan University, Taiwan
}

Wire breakage and unstable machining drastically reduce the machining efficiency and accuracy in wire electrical discharge machining (WEDM). When a stair-shaped workpiece is machined, poor electrolyte flow around the steps leads to wire rupture or unstable machining. This paper presents a WEDM adaptive control system that maintains optimal machining and improves the stability of machining at the stair section where workpiece thickness changes. A three-layer back propagation neural network is used to estimate the thickness of a workpiece. The developed adaptive control system is executed in the hierarchical structure of three control loops, using fuzzy control strategy. In the first control loop, the total sparking frequency is controlled within a safe level for wire rupture suppression. In the second control loop, the proportion of abnormal sparks is maintained at a pre-determined level for process control purposes. Based on the estimated thickness of a workpiece, adaptive parameter optimisation is carried out to determine the optimal machining settings and to provide the reference targets for the other two control loops. Experimental results demonstrate that the workpiece height can be estimated by using a feed-forward neural network. The developed adaptive control system results in faster machining and better machining stability than does the commonly used gap voltage control system.

Keywords: Adaptive control; Fuzzy control strategy; Neural networks; WEDM

\section{Introduction}

Wire breakage and unstable machining drastically reduce the machining efficiency and accuracy in wire electrical discharge machining (WEDM). When a stair-shaped workpiece is machined, poor electrolyte flow around the steps and workpiece

Correspondence and offprint requests to: M. T. Yan, Department of Mechanical Engineering, Huafan University, No. 1, Huafan Road, Shihtin Hsiang, 223 Taipei Hsien, Taiwan, R.O.C. E-mail: mtyan@ huafan.hfu.edu.tw edges leads to wire rupture or unstable machining. In order to carry out the processing of such a workpiece, a conservative machining setting is commonly used, but, the machining speed is greatly reduced. Many on-line monitoring and control systems have been developed for the improvement of WEDM performance that includes wire rupture prevention, machining efficiency, and stability. Some adaptive control systems employed short sparks and sparking frequency as sensing parameters to monitor and control wire rupture suppression [1-3]. Higher-power density along the wire electrode resulting from a great number of short sparks or the sudden increase of sparking frequency, contributes to wire rupture. Based on the detection of spark locations on-line, an adaptive control system has been developed to reduce the concentration of discharges at any point and thus to reduce wire breakage [4]. A control system has been developed to reduce the risk of wire rupture based on a thermal model. The model is used to perform an on-line calculation of the temperature distribution over the wire electrode [5]. Wire breakage can be avoided by these control systems, but they do not guarantee optimal and high-speed machining. An expert system for control of the WEDM process has been developed [6]. However, a large amount of computation is required because of the slow learning speed, so it does not work satisfactorily for on-line control purposes. An adaptive control system has therefore been developed to optimise the on-line sparking frequency by estimating the workpiece height with a multi-input model $[7,8]$. Since the parameters of the proposed model rely heavily on machining conditions, a great number of experiments and statistical techniques are required to derive the explicit mathematical model.

The WEDM metal removal process is characterised by nonlinear, stochastic and time-varying characteristics. Moreover, the process features change drastically with machining parameters. A precise mathematical model describing the WEDM process is difficult to obtain. Hence, classical control strategy and modern control technology based on a well-defined mathematical model are not applicable for a wide variety of machining conditions. Since a fuzzy control strategy does not need a mathematical model and its control structure is insensitive to variations of process dynamics and noise disturbance, this control strategy has proved to be successful in various complex 
processes where mathematical models are unknown or illdefined [9]. Fuzzy control strategy has been applied to the adaptive control of the WEDM process in our previous studies $[10,11]$. However, lack of on-line estimation of the workpiece height may cause the system not to run properly when a stairshaped workpiece is machined. Artificial neural networks have been implemented in various manufacturing fields such as tool breakage monitoring, inverse modelling of the cutting process and monitoring machining processes [12]. The neural network approach has also been applied to modelling and on-line monitoring of the EDM process [13,14]. This paper presents a WEDM adaptive control system that maintains optimal machining conditions and improves the stability of machining at stair sections where the workpiece thickness changes. A threelayer back-propagation neural network is used to estimate the thickness of the workpiece. The developed adaptive control system is executed in a hierarchical structure of three control loops by using a fuzzy control strategy. In the first control loop, the total sparking frequency is monitored and controlled within a safe level for wire rupture suppression. The proportion of abnormal sparks is maintained at a pre-determined level for process control purposes in the second control loop. In the third control loop, adaptive parameter optimisation is carried out to determine the optimal machining settings and to provide the reference targets for the other two control loops. Experiments demonstrate that the proposed adaptive control system can achieve better machining results than the commonly used gap voltage control system.

\section{Hardware Set-up of the WEDM Adaptive Control System}

Figure 1 shows the hardware set-up of the WEDM adaptive control system $[3,11]$. The control system consists of a flushingtype WEDM machine, a WEDM sparking frequency monitor (composed of a photocouple circuit and an AX5216 counter card), a PC, and an interface for communication between the $\mathrm{PC}$ and the CNC unit of the machine. The WEDM machine is a 5-axis CNC machine with a transistor-controlled power generator. The power generator (composed of a lower-power circuit, a high-power circuit, and a pulse generator) is an isoenergy power supply system. Normal sparks and arc sparks can be discriminated by the pulse generator according to the ignition delay time and the voltage level of each spark. Based on the discrimination of gap status, the discharge durations of normal sparks and arc sparks are controlled and specified by

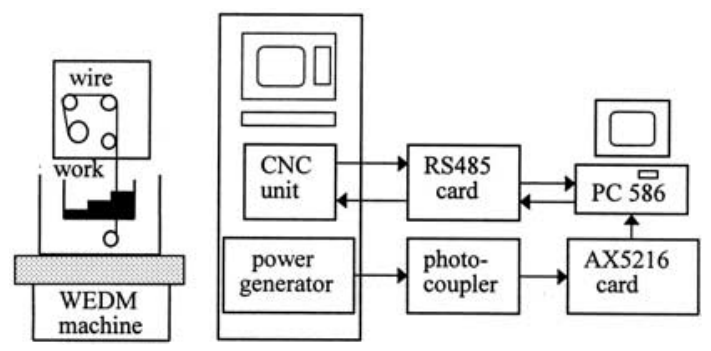

Fig. 1. Hardware set-up of the WEDM adaptive control system. means of on-time and arc on-time settings, respectively. Similarly, the pulse intervals of normal sparks and arc sparks are controlled by off-time and arc off-time settings, respectively. The discharge current of this power supply system has a

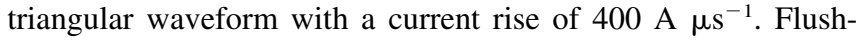
ing pressure can be tuned by a hand valve. The adjustable parameters of this machine include on-time, off-time, arc ontime, arc off-time, servo reference voltage, feedrate override, wire speed, and wire tension, and their working ranges are given in Table 1. Servo reference voltage and feedrate override represent the reference value and the servo gain, respectively, for the gap voltage control system with which this machine is equipped. It is clear that a higher value of servo gain may result in a fast transient response and unstable conditions in the steady state. By using the sparking frequency monitor, total sparks $(N t)$, normal sparks $(\mathrm{Nn})$ and abnormal sparks $(\mathrm{Na})$ (composed of arc discharge and short circuit) in a specific time interval $(\Delta t)$ are detected and counted. A PC/AT-586 is used for calculation and implementation of the control algorithm. The sampling interval is adjustable within the range of 2-65535 ms. Thus, the total sparking frequency $(F t)$ and the proportion of abnormal sparks $\left(n_{a}\right.$, referred as the abnormal ratio) can be computed as $N t / \Delta t$ and $N a / N t$, respectively. An RS485 interface card is employed to handle the I/O (input/output) data and to communicate with the CNC unit through an RS232 port. Through the interface, all machining parameters including power settings and servo reference voltage can be updated, and machining results including average gap voltage and machining feedrate can be accessed in real-time.

\section{On-line Estimation of Workpiece Height by Using Neural Network}

Because of the stochastic nature of the discharge mechanism, it is still not easy to describe the WEDM process by an explicit mathematical model. In order to reduce the complexity and difficulty in deriving the workpiece height based on a mathematical model, a feedforward neural network is adopted here to estimate the workpiece height. The feedforward neural network is composed of many interconnected processing elements, called neurons or nodes, which operate in parallel, and can be grouped into input, hidden, and output layers. The outputs of nodes in one layer are transmitted to nodes in another layer through connections that amplify or attenuate the outputs through weight factors. An artificial neuron is divided

Table 1. Adjustable parameter of the WEDM machine.

\begin{tabular}{ll}
\hline Items & Range \\
\hline On-time & $0.1-0.9 \mu \mathrm{s}(9$ steps $)$ \\
Off-time & $8-50 \mu \mathrm{s}(43$ steps $)$ \\
Arc on-time & $0.1-0.5 \mu \mathrm{s}$ (5 steps) \\
Arc off-time & $9-50 \mu \mathrm{s}(42 \mathrm{steps})$ \\
Servo reference voltage & $30-70 \mathrm{~V}$ \\
Feedrate override & $0-310 \%$ \\
Wire speed & $1-15 \mathrm{~mm} \mathrm{~min}^{-1}(15 \mathrm{steps})$ \\
Wire tension & $500-2500 \mathrm{gf}(15 \mathrm{steps})$
\end{tabular}


into two parts: a summation function and an activation function. The summation function for all of the inputs is calculated by

$$
n e t_{j}^{n}=\sum_{i} W_{j i} O_{i}^{n-1}-\theta_{j}^{n}
$$

where $n e t_{j}^{n}$ is the summation function of the $j$ th neuron in the $n$th layer, $W_{j i}$ is the weight from the $i$ th neuron in the $(n-1)$ th layer. $O_{i}^{n-1}$ is the output of the $i$ th neuron in the $(n-1)$ th layer. $\theta_{j}^{n}$ is the threshold value of the $j$ th neuron in the $n$th layer. The neuron performs nonlinear mapping of the result of the summation function through its activation function and then determines the output. The output of the neuron is then transmitted along the outgoing connections to serve as an input to subsequent neurons. In the present study, a sigmoid function is used as the activation function. The output of the $j$ th neuron for the $n$th layer can be expressed as

$$
O_{j}^{n}=f\left(n e t_{j}^{n}\right)=\frac{1}{1+n e t_{j}^{n}}
$$

The connection weights are adapted properly using the backpropagation learning algorithm [15], which uses a gradientdescent technique to minimise the summation of the squared error between the calculated output of the network and the desired output. Thus, the weights in the $n$th layer are modified by an amount $\Delta W_{j i}^{n}$, given by

$$
\Delta W_{j i}^{n}(k)=-\eta \frac{\partial E}{\partial W_{j i}^{n}}+\alpha \Delta W_{j i}^{k}(k-1)
$$

where $E$ represents the squared error, $\eta$ is the learning rate, $\alpha$ is the momentum coefficient, and $k$ is the number of the current iteration. In a multilayer neural network, the weights of the nodal connection are randomly set and modified. A large number of iterations are required to back-propagate the error until an acceptable error tolerance level is achieved through the training process. The training of the network is carried out off-line.

In this study, total sparking frequency, normal sparking frequency, arc sparking frequency, abnormal ratio, average gap voltage, real feedrate, variation of average gap voltage, and variation of feedrate are employed as input signals for the input layer of the neurons. The variation of gap voltage is specified as the difference between the mean value of ten successive sampling gap voltages and the current sampling gap voltage. Similarly, the variation of feedrate is specified as the difference between the mean value of ten successive sampling feedrates and the current sampling feedrate. Average gap voltage and feedrate change drastically when the machining plate thickness is varied. Thus, change of average gap voltage and change of feedrate can be used as input signals to the neuron to distinguish a stable machining status from a transient machining status. Hence, the output layer of the neural network has two nodes, which represent the workpiece height and the machining status, respectively. The output value of the machining status ranges between zero and one. Stable machining status and transient machining status are specified as zero and one, respectively, during the training of the neural networks. In our case, a feedforward neural network of the 8-9-2 type with back-propagation learning is used here to estimate the workpiece height and distinguish the machining status. The sampling

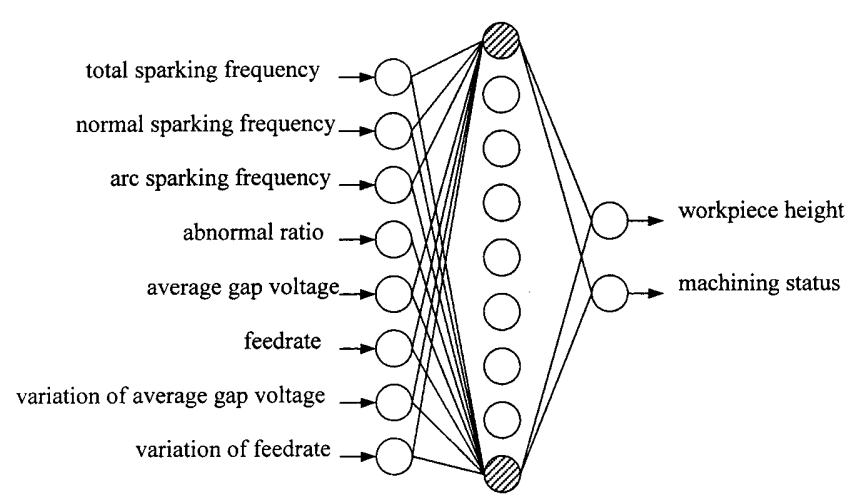

Fig. 2. Schematic diagram of the neural network for the estimation of the workpiece height.

interval for data acquisition is $200 \mathrm{~ms}$. Figure 2 shows a net schematic diagram of the neural work for the estimation of the workpiece height.

\section{Hierarchical Adaptive Control of WEDM}

Figure 3 shows a schematic diagram of the hierarchical adaptive control system. The developed adaptive control system is executed in a hierarchical structure of three control loops by using fuzzy control strategy. In the first control loop, the total sparking frequency is controlled within a safe level for wire rupture suppression. In the second control loop, the proportion

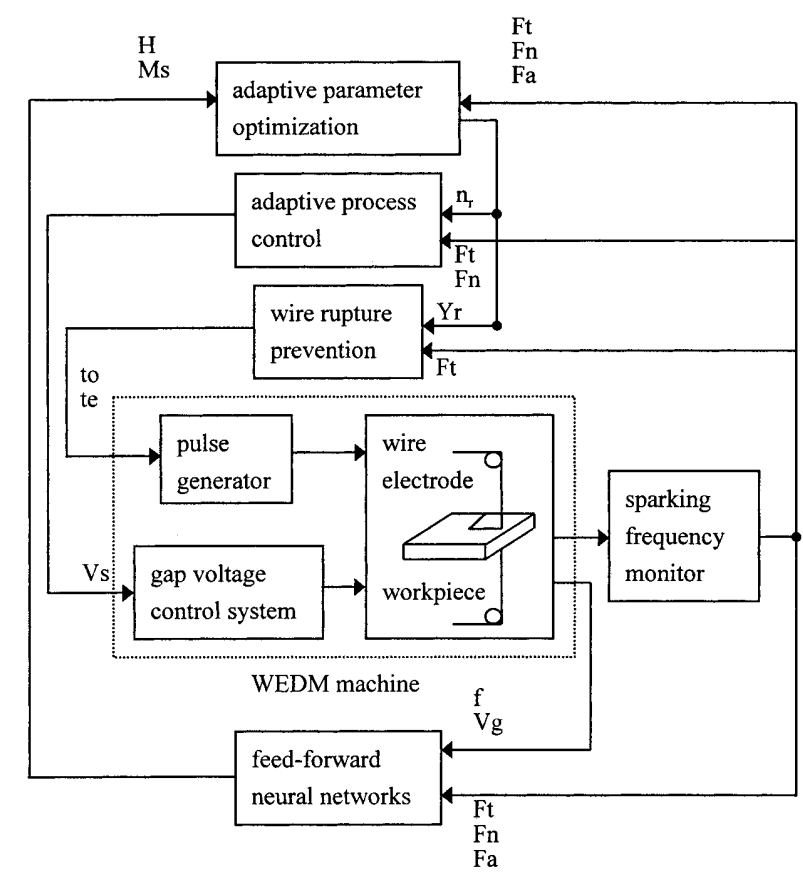

Fig. 3. Schematic diagram of the hierarchical adaptive control system. to, pulse interval time; te, discharge duration; $f$, feedrate; $V s$, servo reference voltage; $V g$, average gap voltage; $F t$, total sparking frequency; $F n$, normal sparking frequency; $F a$, arc sparking frequency; $Y r$, reference frequency; $n_{r}$, reference ratio; $H$, estimated workpiece height; $M s$, machining status. 
of abnormal sparks is maintained at a pre-determined level by regulating the servo reference voltage for process control purposes. Based on the estimated thickness of the workpiece through the feedforward neural network, adaptive parameter optimisation is implemented for the third loop by determining the optimal machining settings and providing the reference targets for the other two control loops during machining. A fuzzy controller uses a set of linguistic control rules related by the dual concepts of fuzzy implication and the composition rule of inference. In essence, the fuzzy controller provides a useful tool for converting heuristic control rules based on an expert's knowledge or an operator's experience into an automatic control strategy. The rule-based control strategy is often designed to simulate human experience and human intelligence. A typical fuzzy logic controller consists of four major parts: a fuzzifiation interface, a knowledge base, decision-making logic, and a defuzzification interface. A detailed discussion on the design of fuzzy controllers for adaptive control of the WEDM process is presented in the following subsections.

\subsection{Adaptive Control for Wire Rupture Suppression}

When a stair-shaped workpiece is machined, poor electrolyte flow around step shapes leads to a sudden rise of sparking frequency, which causes wire rupture or unstable machining. Therefore, the sparking frequency should be controlled within a safe level in order to suppress wire breaking and unstable machining [3]. In response to the sudden rise of sparking frequency, a fuzzy controller is provided by adjusting the pulse interval time (to) and discharge duration (te). Once the sparking frequency is controlled within a safe level, the control parameters are restored to their initial values to maintain an optimal machining speed. Error and change of error are two variables commonly adopted for the input of a fuzzy logic controller. A scale mapping is carried out beforehand that transfers the range of values of the input variables into the corresponding universe of discourse. The linguistic variables to be used in the premise of control rules are defined as follows:

$$
\begin{aligned}
& e_{1} \equiv \text { sparking frequency error } \\
& =(\text { reference frequency }- \text { sparking frequency }) \times G E_{1}
\end{aligned}
$$

and

$$
\begin{aligned}
c e_{1} \equiv & \text { change of sparking frequency error } \\
= & \text { (current frequency error }- \\
& \text { previous frequency error }) \times G C E_{1}
\end{aligned}
$$

where $G E_{1}$ and $G C E_{1}$ are scaling factors and their values are found to be 15 and 10, respectively. Five linguistic sets for the domains of definition denoted by NB, NS, ZO, PS and PB are specified, where $\mathrm{P}, \mathrm{B}, \mathrm{S}, \mathrm{N}$ and $\mathrm{ZO}$ correspond, respectively, to positive, big, small, negative and zero. An isosceles triangle-shaped function is chosen as the membership function of each linguistic set for the input and output of the controller. Twenty-five control rules are formulated, as shown in Table 2 . The max-min inference method and the mean of maximum method are used to perform fuzzy reasoning and defuzz-
Table 2. Rule base of the fuzzy controller for wire rupture prevention.

\begin{tabular}{llllll}
\hline $\begin{array}{l}\Delta u_{1} \\
e_{1} / c e_{1}\end{array}$ & PB & PS & ZO & NS & NB \\
\hline PB & PB & PB & PS & ZO & NS \\
PS & PS & PS & PS & NS & NS \\
ZO & PS & NS & ZO & NS & NB \\
NS & NS & NS & NB & NB & NB \\
NB & NB & NB & NB & NB & NB \\
$\Delta u_{2}$ & & & & & \\
PB & ZO & ZO & ZO & ZO & ZO \\
PS & ZO & ZO & ZO & ZO & ZO \\
ZO & ZO & ZO & ZO & ZO & ZO \\
NS & NS & NS & NS & NS & NS \\
NB & NB & NB & NB & NB & NB \\
\hline
\end{tabular}

ification, respectively [16]. The real control parameters applied to the pulse generator are calculated from,

$$
\begin{aligned}
& u_{t o}(k)=u_{t o}(k-1)+\Delta u_{1}(k) \\
& u_{t e}(k)=u_{i}+\Delta u_{2}(k)
\end{aligned}
$$

where $u_{t o}(k)$ represents the control signal at the $k$ th sampling instance, and it is defined as the reciprocal of pulse interval time (to), i.e. $t o=1 / u_{\text {off }}, u_{t e}(k)$ represents the discharge duration (te) at the $k$ th sampling instance, $u_{i}$ stands for the initial value of discharge duration, $\Delta u_{1}$ and $\Delta u_{2}$ are the output of the fuzzy controller.

\subsection{Adaptive Process Control}

The objective of adaptive process control of WEDM is to maintain a high metal removal rate during roughing, and optimal and stable machining during finishing. A fuzzy controller is designed for adaptive process control by means of controlling the proportion of abnormal sparks at an optimal level. The optimal value of the abnormal ratio is $40 \%-60 \%$, as shown in our previous study [10]. The linguistic variables used in the premise of the fuzzy controller are abnormal ratio error $\left(e_{2}\right)$ and change of the abnormal ratio error $\left(c e_{2}\right)$. The functional relationship represented by such a fuzzy controller can be described as

$$
\Delta u_{s}=F\left(e_{2}, c e_{2}\right)
$$

where $\Delta u_{s}$ represents the output of the controller, and $F(\cdot)$ stands for the nonlinear relationship of the fuzzy controller. The domain of the input variables and the output variable are divided into seven fuzzy subsets, "Negative big", "Negative medium", "Negative small", "Zero", "Positive small", "Positive medium", "Positive big" and their domain ranges from -3 to 3. An isosceles triangle-shaped function is also chosen as the membership function of each linguistic set. Forty-nine fuzzy rules are designed according to the following concept. If the abnormal ratio is larger than the reference value, the servo reference voltage should be increased to improve the poor gap condition. If the abnormal ratio is lower than the pre-determined level, the servo reference voltage should be decreased to maintain an optimal machining speed. The fuzzy control rules 
Table 3. Rule base of the fuzzy controller for adaptive process control.

\begin{tabular}{|c|c|c|c|c|c|c|c|}
\hline $\begin{array}{l}\Delta u_{s} \\
e_{2} / c e_{2}\end{array}$ & PB & $\mathrm{PM}$ & PS & $\mathrm{ZO}$ & NS & NM & $\mathrm{NB}$ \\
\hline PB & NB & NB & NB & NB & $\mathrm{NM}$ & NM & $\mathrm{NM}$ \\
\hline PM & NB & NB & $\mathrm{NM}$ & $\mathrm{NM}$ & $\mathrm{NM}$ & $\mathrm{NM}$ & $\mathrm{NM}$ \\
\hline PS & $\mathrm{NM}$ & NM & NM & NS & NS & NS & NS \\
\hline $\mathrm{ZO}$ & NM & NS & NS & $\mathrm{ZO}$ & NS & PS & PS \\
\hline NS & PS & PS & PS & PS & PS & PS & PS \\
\hline NM & PM & PM & PM & PM & PM & PM & $\mathrm{PM}$ \\
\hline NB & PB & PB & PB & PB & PB & PB & PB \\
\hline
\end{tabular}

are given in Table 3 . The max-min inference method and the mean of maximum method are also used to carry out fuzzy reasoning and defuzzification, respectively. The servo reference voltage applied to the gap voltage control system is calculated by

$$
u_{s}(k)=u_{s}(k-1)+\Delta u_{s}(k)
$$

where $u_{s}(k)$ represents the servo reference voltage setting at the $k$ th sampling instance, and $\Delta u_{s}$ is the output of the fuzzy controller.

\subsection{Adaptive Parameter Optimisation}

The control loop for adaptive parameter optimisation aims to select the machining setting and to adjust the reference values for the other two control loops. The decision to carry out the control loop of parameter optimisation or not depends on the stability of machining conditions and the machining status from the neural network. A stability percentage (SP) is defined as the performance index to evaluate the machining condition, and it is expressed as

$$
S P=\left(1-\frac{n_{a}(k)-n_{a}(k-1)}{n_{r}}\right) \times 100 \%
$$

where $n_{a}(k)$ represents the proportion of abnormal sparks at the $k$ th sampling instance, and $n_{r}$ stands for the abnormal ratio reference. The machining condition is referred to as stable machining if the stability percentage is greater than $95 \%$, and vice versa. If stable machining is maintained for 150 sampling intervals $(200 \mathrm{~ms})$ and the machining status is less than 0.2 , a rule-based control strategy is carried out to control the machining parameters at the optimal setting. As shown in Table 4, a specific rule is selected according to the on-line estimated

Table 4. Rule base for the control loop of adaptive parameter optimisation.

\begin{tabular}{llll}
\hline $\begin{array}{l}\text { Workpiece } \\
\text { height }\end{array}$ & $\begin{array}{l}\text { Machining } \\
\text { setting }\end{array}$ & $\begin{array}{l}\text { Reference } \\
\text { ratio }\end{array}$ & $\begin{array}{l}\text { Reference } \\
\text { frequency }\end{array}$ \\
\hline $0-H_{1}$ & $\mathrm{~S}_{1}$ & $\mathrm{R}_{1}$ & $\mathrm{~F}_{1}$ \\
$H_{1}-H_{2}$ & $\mathrm{~S}_{2}$ & $\mathrm{R}_{2}$ & $\mathrm{~F}_{2}$ \\
$H_{2}-H_{3}$ & $\mathrm{~S}_{3}$ & $\mathrm{R}_{3}$ & $\mathrm{~F}_{3}$ \\
$\ldots$ & $\ldots$ & $\ldots$ & $\ldots$ \\
$H_{n-1}-H_{n}$ & $\mathrm{~S}_{\mathrm{n}}$ & $\mathrm{R}_{\mathrm{n}}$ & $\mathrm{F}_{\mathrm{n}}$ \\
\hline
\end{tabular}

workpiece height. For example, if the estimated workpiece height ranges from $H_{n-1}$ to $H_{n}$, the machining parameters, the abnormal ratio reference and the reference sparking frequency are set to $S_{n}, R_{n}$, and $F_{n}$, respectively.

\section{Experimental Results}

The developed neural networks and adaptive control strategies are implemented in a PC/AT using the $\mathrm{C}$ language. The sampling intervals for adaptive control for wire rupture suppression, adaptive process control and adaptive parameter optimisation are $200 \mathrm{~ms}, 2 \mathrm{~s}$, and $30 \mathrm{~s}$, respectively. Some experiments are conducted under the conditions of machining a workpiece with a sudden increase in height, a sudden decrease in height, or with a constant slope, to verify the applicability of the proposed adaptive control system. Machining settings and reference values used in the experiments is given in Table 5. The experimental results are presented compared with those of a gap voltage control system commonly used in commercialised WEDM machines.
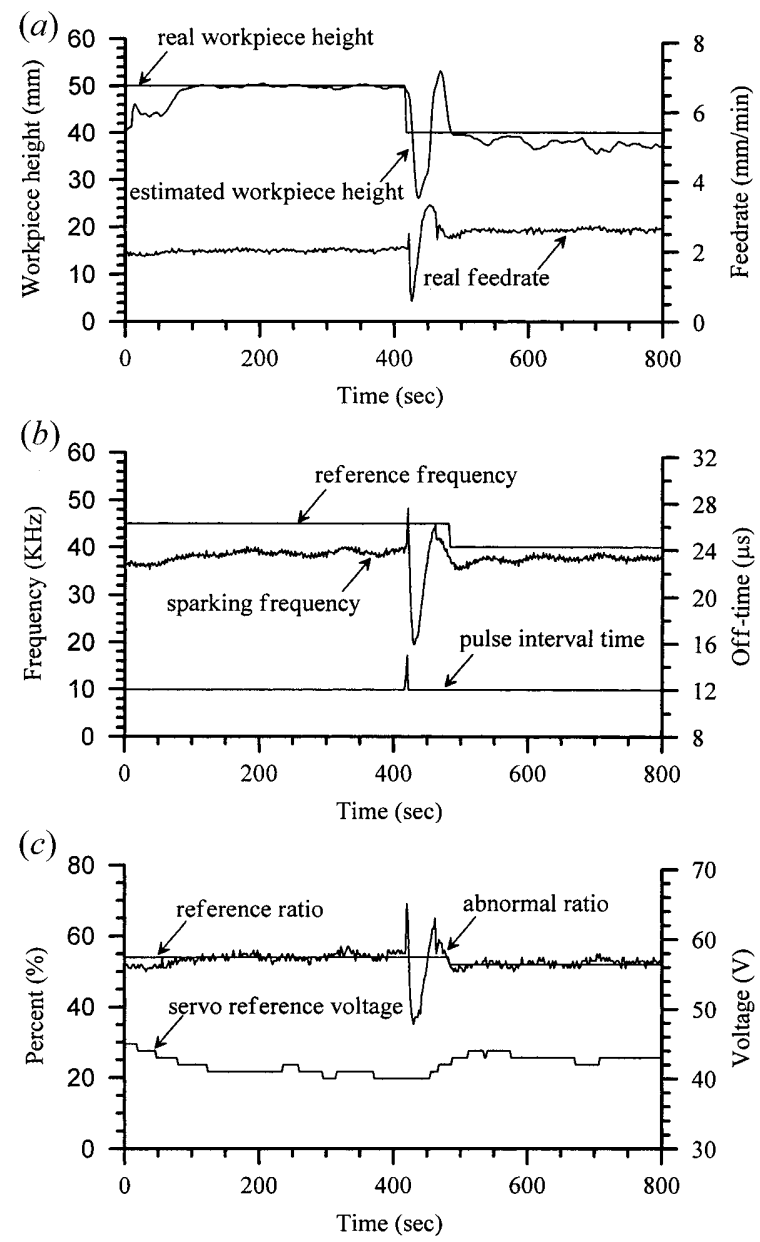

Fig. 4. (a) Estimated workpiece height and real feedrate, $(b)$ sparking frequency and pulse interval time, and $(c)$ abnormal ratio and servo reference voltage with adaptive control system when a workpiece with a sudden decrease in height is machined. 
Table 5. Machining setting and reference values used in the experiments

Workpiece: SKD11 tool steel

Wire electrode: Brass $0.25 \mathrm{~mm}$ diameter

Wire feed: $7 \mathrm{~m} \mathrm{~min}^{-1}$; Wire tension: $1000 \mathrm{gf}$

Upper water pressure: 6.5 bar; Lower water pressure: 11 bar

\begin{tabular}{lllllll}
\hline $\begin{array}{l}\text { Workpiece } \\
\text { height } \\
(\mathrm{mm})\end{array}$ & $\begin{array}{l}\text { On } \\
\text { time } \\
(\mu s)\end{array}$ & $\begin{array}{l}\text { Off } \\
\text { time } \\
(\mu s)\end{array}$ & $\begin{array}{l}\text { Arc on } \\
\text { time } \\
(\mu s)\end{array}$ & $\begin{array}{l}\text { Arc off } \\
\text { time } \\
(\mu s)\end{array}$ & $\begin{array}{l}\text { Reference } \\
\text { ratio } \\
(\%)\end{array}$ & $\begin{array}{l}\text { Reference } \\
\text { frequency } \\
(\mathrm{kHz})\end{array}$ \\
\hline $28-33$ & 0.9 & 12 & 0.4 & 18 & 48 & 36 \\
$33-38$ & 0.9 & 12 & 0.4 & 18 & 50 & 38 \\
$38-43$ & 0.9 & 12 & 0.5 & 18 & 53 & 40 \\
$43-48$ & 0.9 & 12 & 0.5 & 18 & 53 & 45 \\
$48-53$ & 0.9 & 12 & 0.5 & 18 & 54 & 45 \\
\hline
\end{tabular}

Figure 4 shows the machining results with an adaptive control system when a workpiece with a sudden decrease in height is machined. As shown in Fig. 4(a), the estimated workpiece height can follow the real workpiece thickness during machining. Figure $4(b)$ demonstrates that the adaptive control system can control the sparking frequency within a reference level by adjusting the pulse interval time. Figure 4(c) demonstrates that the abnormal ratio can be controlled to a
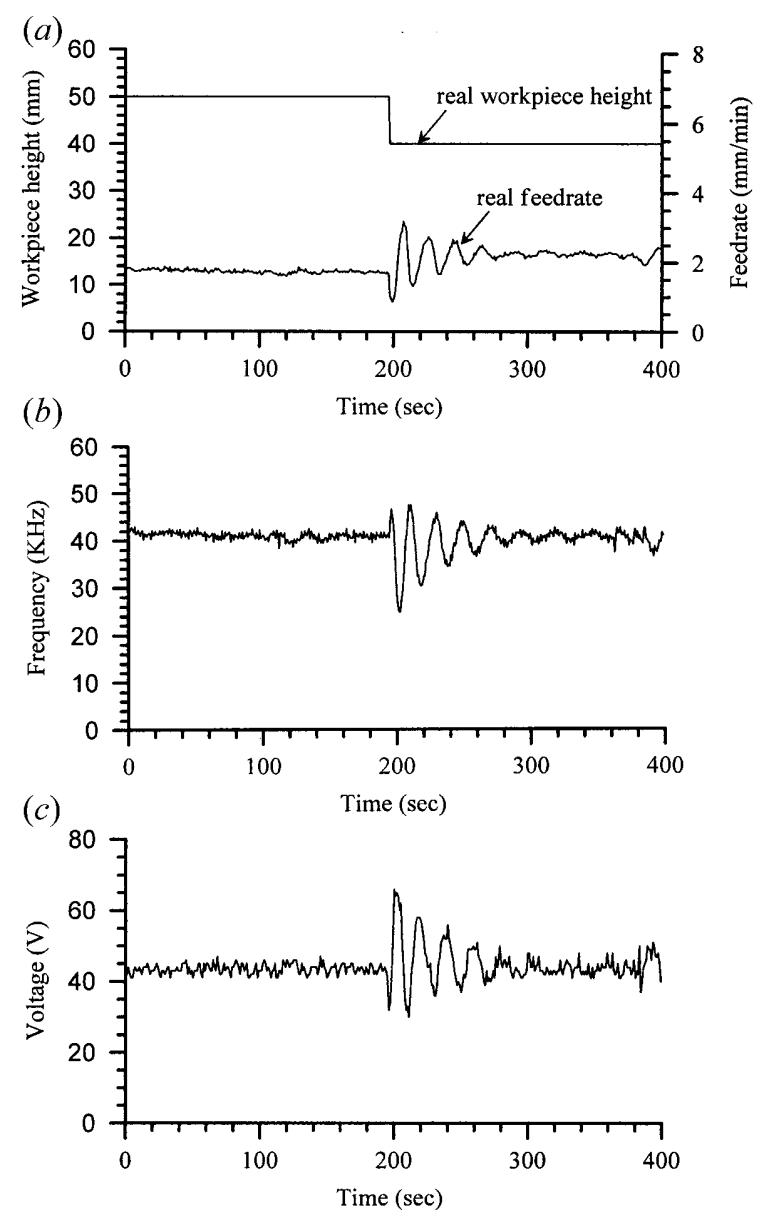

Fig. 5. (a) Real feedrate, (b) sparking frequency, and (c) average gap voltage with gap voltage control system when a workpiece with a sudden decrease in height is machined. pre-determined level by adjusting the servo reference voltage. Figure 5 shows the machining results with the gap voltage control system under the same conditions as Fig. 4. As illustrated in Fig. 5, poor flushing conditions lead to unstable machining at the stair section where the workpiece thickness changes. The adaptive control system enables the stability of machining conditions and the machining speed to improve by
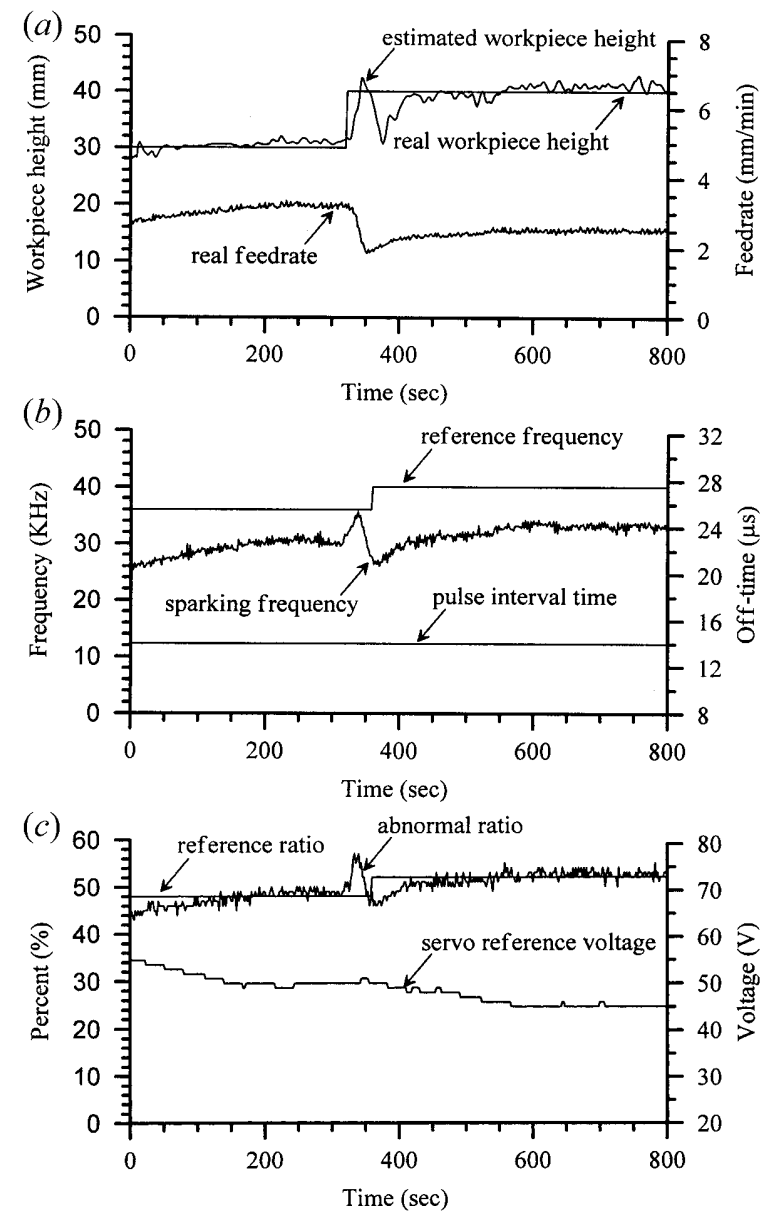

Fig. 6. (a) Estimated workpiece height and real feedrate, $(b)$ sparking frequency and pulse interval time, and $(c)$ abnormal ratio and servo reference voltage with adaptive control system when a workpiece with a sudden increase in height machined. 
$15 \%$ compared with the commonly used gap voltage control system. Figure 6 shows the machining results using an adaptive control system when a workpiece with a sudden increase in height is machined. For comparison purposes, the same test with gap voltage control system is conducted and the recorded data is shown in Fig. 7. By comparing Figs 6 and 7, it can be seen that the adaptive control system is capable of improving the machining speed and properly estimating the workpiece height within an acceptable accuracy of $1.6 \mathrm{~mm}$. Figure 8 shows the experimental results of the adaptive control system when a workpiece with a constant slope height is machined. This figure indicates that the estimated workpiece height is similar to the real workpiece profile. The developed adaptive control system can adapt suitable machining parameters to the gradual decrease in workpiece height.

\section{Discussion}

Having described the experiments on the hierarchical adaptive control system for the WEDM process, some issues when applying the neural network to the developed adapative control system for wire rupture prevention are addressed in the follow-
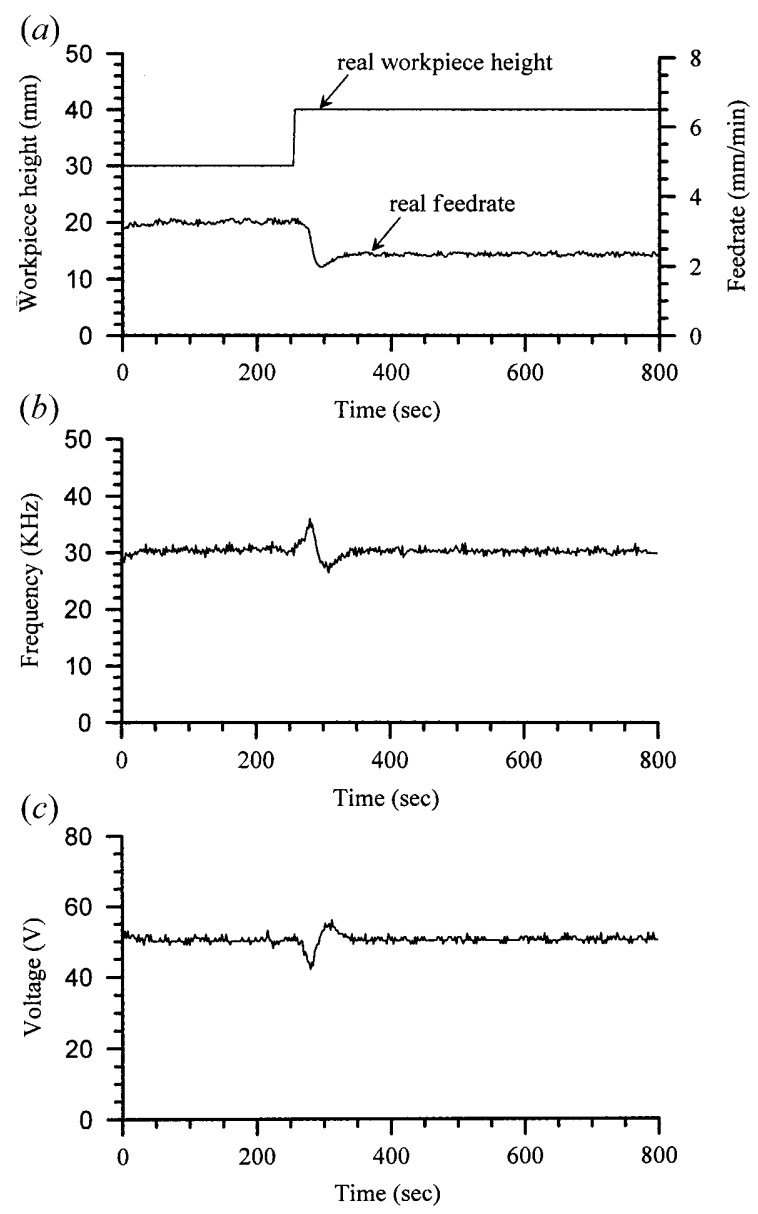

Fig. 7. (a) Real feedrate, (b) sparking frequency, and (c) average gap voltage with gap voltage control system when a workpiece with a sudden increase in height is machined. ing discussion. In order to enhance the potential of a practical application, two approaches to applying the neural networks to the WEDM process are considered. For the first approach, the neural networks are trained under constant power settings and the corresponding weighting factors are recorded and stored in a memory space. Thus, networks can be applied to different machining conditions using the memory-based weighting factors. For the second approach, the networks have power condition information by incorporating power settings as input signals. Since the process parameters are incorporated into the learning process, the networks are expected to operate well for a wide variety of machining conditions.

Two types of wire-breaking phenomenon have been found and identified from our previous investigation [3,17]. The first type is a sudden rise of total sparking frequency, and the duration of deterioration ranges from $50 \mathrm{~ms}$ to $2 \mathrm{~s}$. This type of wire rupture often occurs when the machining conditions, particularly the discharge duration or the flushing pressure, are changed during the machining process. In the second type of wire breaking, the sparking frequency increases slightly and the duration of the premonitory symptoms lasts for $10 \mathrm{~s}$ or more. This kind of wire breaking often takes place when a
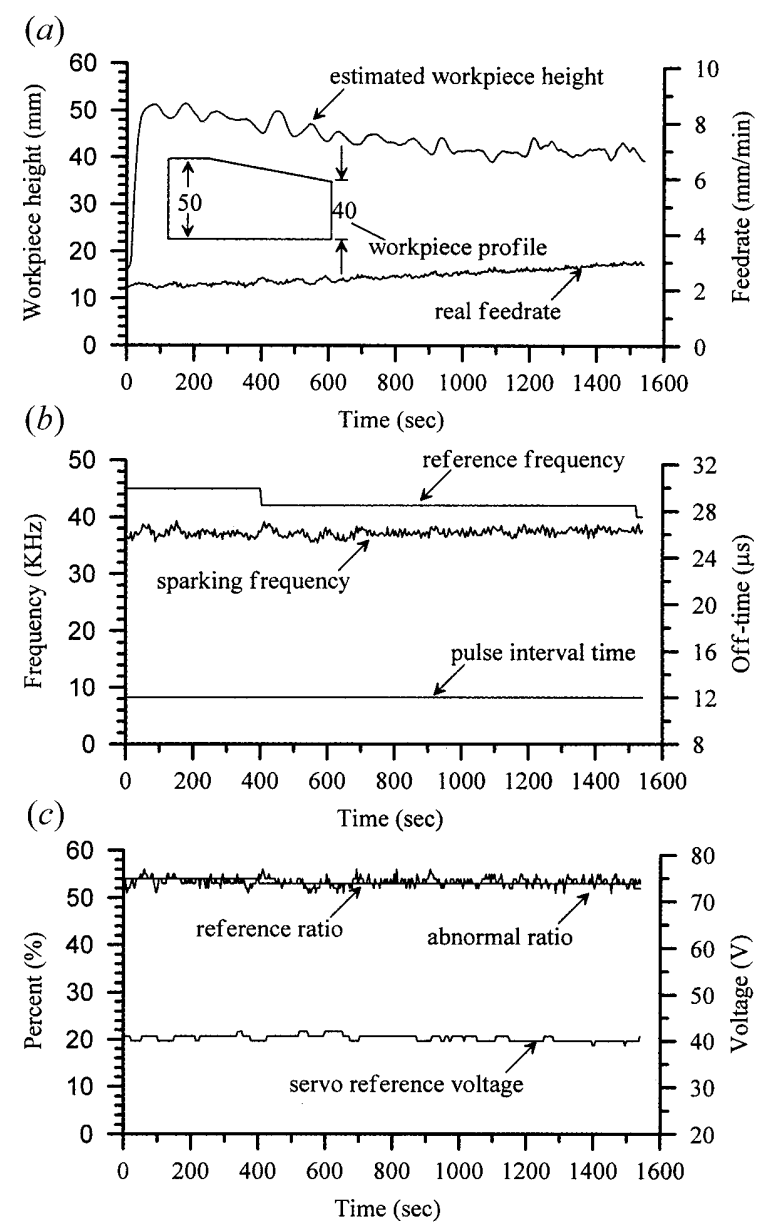

Fig. 8. (a) Estimated workpiece height and real feedrate, (b) sparking frequency and pulse interval time, and $(c)$ abnormal ratio and servo reference voltage with adaptive control system when a workpiece with a constant slope height is machined. 
stair-shaped workpiece is machined or a workpiece is machined under poor flushing conditions. Some workers have also shown that wire rupture may happen in a short time $(5-40 \mathrm{~ms})[1,2]$. Thus, the developed adaptive control system may not respond promptly and properly to some poor machining conditions in a short time $(5 \mathrm{~ms})$ because of the bottleneck caused by communication delays and real-time control in a PC. Nevertheless, the developed system can reduce the possibility of wire rupture and improve the stability of machining at some difficult machining conditions that include some of the first and second types of wire breaking processes. To enhance the potential of avoiding wire rupture in all machining conditions, the developed adaptive control system should be implemented using a DSP-based control card or a hardware control module which is directly linked to the power supply system of a WEDM machine. Such an adaptive control system will increase the hardware cost. Development of a DSP-based machining process monitoring and control system is under way.

\section{Conclusion}

A feedforward neural network is presented using a backpropagation learning algorithm for the estimation of the workpiece height in WEDM. The average error of workpiece height estimation is $1.6 \mathrm{~mm}$, and the transient response to change in workpiece height is reasonably satisfactory. The developed adaptive control system is carried out in three hierarchical levels using a fuzzy control strategy. The sparking frequency is controlled within a safe level for wire rupture suppression, and the abnormal ratio is also controlled at the optimal level when a workpiece with variable height is machined. Experimental results also show that the neural network approach and fuzzy control strategy are suitable for such an uncertain and complicated process. The developed hierarchical adaptive control system enables the machining stability and the machining speed to be improved by $15 \%$ compared with a commonly used gap voltage control system.

\section{References}

1. N. Kinoshita, M. Fukui and G. Gamo, "Control of wire-EDM preventing electrode from breaking", Annals CIRP, 31(1), pp. 111114,1982
2. K. P. Rajurkar and W. M. Wang "On-line monitor and control for wire breakage in WEDM", Annals CIRP, 40(1), pp. 219222, 1991.

3. M. T. Yan and Y. S. Liao, "Monitoring and self-learning fuzzy control for wire rupture prevention in wire electrical discharge machining", International Journal of Machine Tools and Manufacture, 36(3), pp. 339-353, 1996.

4. K. Shoda, Y. Kaneko, H. Nishimura, M. Kunieda and M. X. Fan, "Adaptive control of WEDM with on-line detection of spark locations", Proceeding of 10th International Symposium for Electro-Machining (ISEM-10), pp. 410-416, 1992.

5. B. Lauwers, J. P. Kruth, Ph. Bleys, B. Van Coppenolle, L. Stevens and R. Derighetti, "Wire rupture using on-line pulse localization in WEDMB", Proceeding of 12th International Symposium for Electro-Machining (ISEM-12), pp. 203-213, 1998.

6. W. Dekeyser, R. Snoeys and M. Jennes, "Expert system for wire cutting EDM, based on pulse classification and thermal modeling", Robotics and Computer-Integrated Manufacturing, 4(1/2), pp. 219224, 1988.

7. K. P. Rajurkar, W. M. Wang and J. A. McGeugh, "WEDM identification and adaptive control for variable height components", Annals CIRP, 43(1), pp. 199-202, 1994.

8. K. P. Rajurkar, W. M. Wang and W. S. Zhao, "WEDM-adaptive control with a multiple input model for identification of workpiece height", Annals CIRP, 46(1), pp. 147-150, 1997.

9. M. Sugeno, Industrial Application of Fuzzy Control, North-Holland Amsterdam, 1985.

10. M. T. Yan and Y. S. Liao, "Adaptive control of WEDM process using the fuzzy control strategy", Journal of Manufacturing Systems, 17(4), pp. 263-274, 1998.

11. Y. S. Liao and J. C. Woo, "A new fuzzy control system for the adaptive control of WEDM process", Proceeding of 12th International Symposium for Electro-Machining (ISEM-12), pp. 193202, 1998.

12. J. Prohaszka, "A step toward intelligent manufacturing: modeling and monitoring of manufacturing processes through artificial neural networks", Annals CIRP, 42(1), pp. 485-488, 1993.

13. T. A. Spedding and Z. Q. Wang, "Study on modeling of wire EDM process", Journal of Materials Processing Technology, 69, pp. 18-28, 1997.

14. J. Y. Kao and Y. S. Tarng, "A neural-network approach for the on-line monitoring of the electrical discharge machining process", Journal of Materials Processing Technology, 69, pp. 112-119, 1997.

15. J. M. Zurada, Introduction to Artificial Neural Systems, West, 1992.

16. C. C. Lee, "Fuzzy logic in control systems: fuzzy logic controller Part I and Part II," IEEE Transactions on Systems, Man, and Cybernetics, 20(2), pp. 404-435, 1990.

17. Y. S. Liao, Y. Y. Chu and M. T. Yan, "Study of wire breaking process and monitoring of WEDM", International Journal of Machine Tools and Manufacture, 37(4), pp. 555-567, 1997. 